\title{
Amphetamine Versus Non Amphetamine-Related First Episode Psychosis in Saudi Arabian Patients
}

\author{
Ehab Said El-Desoky, Ashraf M. A. El-Tantawy, Yasser M. Raya, Abdulhameed Al-Yahya
}

Pharmacology Department, Faculty of Medicine, Assiut University, Asyut, Egypt.

Email: ehegypt@yahoo.com, ehegypt@gmail.com

Received January $14^{\text {th }}, 2011$; revised March $5^{\text {th }}, 2011$; accepted May $15^{\text {th }}, 2011$.

\begin{abstract}
Background: Amphetamines are illicit psychostimulant drugs that can induce psychotic symptoms. Very few studies have been conducted in Kingdom of Saudi Arabia (SA) on amphetamine abuse and related psychosis. Recently, the pattern of amphetamine abuse in SA showed a significant trend of increased frequency. Objectives: To investigate the extent of amphetamine abuse in a sample of Saudi patients hospitalized for first episode of acute psychosis. Also, to compare in that sample between amphetamine psychosis and other psychoses regarding demographic data, premorbid personality and symptoms profile. Method: 106 patients with acute psychosis were hospitalized and screening of urine for amphetamine was conducted for all. Patients' psychiatric evaluation included interviewing, and ICD-10 criteria for personality disorders. 30 healthy subjects were also included for comparison with patients. Results: 34/106 of psychotic patients $(32 \%)$ were positive for amphetamine in urine $(\geq 1000 \mathrm{ng} / \mathrm{ml})$. The frequency of personality disorders was significantly higher $(P<0.01)$ in the patients $(54 / 106 ; 51 \%)$ compared with healthy subjects $(6 / 30 ; 20 \%)$. Also, the incidence of personality disorders was significantly higher $(P<0.01)$ in amphetamine positive psychosis $(25 / 34 ; 73.5 \%)$ compared with amphetamine negative psychosis $(29 / 72 ; 40 \%)$. Cluster B personality disorders particularly the antisocial and borderline were significantly higher in amphetamine positive psychosis $(13 / 34 ; 38 \%)$ compared with amphetamine negative psychoses $(6 / 72 ; 8 \%)$. The symptom profile showed significant difference between amphetamine positive and amphetamine negative psychosis as regards ideas of reference (50\% vs. 14\%), suspiciousness (44\% vs. $11 \%)$, suicidal ideation (38\% vs. 23\%), paranoid delusions (29\% vs. $17 \%$ ) and increased pulse or blood pressure (29\% vs. $7 \%$ ) respectively. Conclusion: Screening of amphetamine in urine among patients with first episode of acute psychosis can help and support the clinical distinction of amphetamine psychosis from other types of psychosis. This is therapeutically critical since the line of treatment may be different between the two types of psychoses.
\end{abstract}

Keywords: Amphetamine, First Episode Psychosis

\section{Introduction}

In patients with psychosis like schizophrenia and/or bipolar disorder, substance abuse has been reported [1-4]. Previous studies have found high prevalence of schizophrenia and other psychotic disorders among users of illicit substances like cannabis [5] and amphetamines [6, 7]. Recently, a common co-occurrence of first episode psychosis and substance use disorders like cannabis, alcohol and amphetamines has been reported [8-10].

In Saudi Arabia, the rapid development of socioeconomic status and the "oil boom" have led to the adoption of novel recreational attitudes including drug abuse [11]. The annual incidence number of Saudi patients newly admitted to the hospitals with abused drugs is increasing especially for amphetamine at the expense of other sub- stances like heroin, alcohol, and sedatives. The frequency of amphetamine use among Saudi people of 40 years old or less increased markedly in the period 2000-2006 in comparison with the period 1986-1999 [12]. Different sources are available for abused amphetamine preparations by youth in Saudi Arabia like clandestine laboratories and near by countries like Yemen. The high incidence of amphetamine use in Saudi population of young age in addition to the unavailability of any previous studies regarding amphetamine use Saudi psychotic patients have led to designing of this study. The primary aim was to describe the current amphetamine use in a sample of Saudi patients experiencing first episode of acute psychosis through urine screening for the drug. Secondary aims were to find out any points of difference in demographics and clinical picture that 
can help differentiation between first episode psychotic patients who were amphetamine positive and those who were negative for amphetamine.

\section{Patients and Methods}

One hundred six adult Saudi patients attended the Psychiatric Emergency Service of Buraidah Mental Health Hospital in Al-Qassim Governorate, Kingdom of Saudi Arabia in the period from January to July; 2008 and diagnosed as first episode of acute psychosis. Following admission of each patient, one urine sample was collected for amphetamine screening. It was sent immediately to the Toxicology Center of the Ministry of Health. The Axsym analyzer of Abbott using the fluorescence immunoassay technique was used in the screening and a cutoff value $\geq 1000 \mathrm{ng} / \mathrm{ml}$ was considered positive for amphetamine screening. Positive samples then were confirmed by Gas Chromatography Mass Spectrometry (GCMS) technique with cutoff values of $\geq 300 \mathrm{ng} / \mathrm{ml}$ for positive amphetamine samples [13].

\subsection{Clinical Assessment}

Each patient was interviewed (at admission, and then daily) by an expert psychiatrist for clinical and psychiatric assessment. The interview included questionnaire about the socio-demographic data including educational history, employment, socio-economic status, substance use history and family history. Missing data was obtained from patient's relatives to complete the patient profile. Questionnaire about family history included inquiry about family support (e.g. provision of housing, food, clothing and money), parental substance abuse and parental mental illness. All data were analyzed according to the criteria of psychotic illness for diagnosis of acute psychosis, and possible psychoactive substance use as defined by the International Classification of Diseases (ICD-10) [14]. The severity of psychotic symptoms in each patient was evaluated by applying the positive and negative syndrome scale (PANSS). The PANSS scale is a 30-item standardized instrument that measures positive symptoms such as hallucination and delusions, negative symptoms such as affective blunting, emotional withdrawal, and general symptoms such as motor retardation, anxiety, disorientation) using a semi-structured interview and chart review $[15,16]$.

\subsection{Personality Assessment}

During admission period, and once the patient became stable as regards psychotic symptoms, he was assessed by the same expert psychiatrist for any personality disorder and its cluster according to a semi structured interview for personality disorder evaluation $[17,18]$. The clusters examined for personality disorders included:
Cluster A (e.g. schizoid, schizotypal or paranoid), Cluster B (e.g. antisocial, borderline, histrionic or narcissistic) and Cluster C (e.g. avoidant, dependent or obsessive). The study was carried out after approval from the ethical committee, General Directorate of Health Affairs, Al-Qassim Province, Ministry of Health, Kingdom of Saudi Arabia and getting the acceptance of the responsible relatives concerning each patient.

\subsection{Statistical Analysis}

Data analysis was performed with a personal computer using the SPSS statistical software program, version 13 (SPSS, 2002). The comparison of data between the psychotic patients who were amphetamine positive and or negative was based on whether the measurement of the variable was categorical or scaled. Chi-square $(\chi 2)$ test or Fisher's exact test (whenever appropriate) and unpaired t-tests were used to determine the statistical significance of the difference between the variables. Statistical significance was considered at $\mathrm{p}<0.05$.

\section{Results}

Screening of urine samples for amphetamine in all patients $(\mathrm{n}=106)$ revealed positive results in 34 subjects $(32 \%)$. The average concentration of amphetamine in positive urine samples was $6189.8 \pm 634.7 \mathrm{ng} / \mathrm{ml}$. Table 1 showed the demographic features of the psychotic patients whether they were amphetamine positive or negative. Male gender was the most common sex in all patients $(79 / 106 ; 74.5 \%)$ and all amphetamine positive cases were males. The poor family support and history of parental substance abuse were significantly recorded $(p<$ $0.05)$ in amphetamine positive group while the parental mental illness was significantly evident $(p<0.01)$ in amphetamine negative psychotic group. However, low education, unemployment, unmarried status and socioeconomic standard were not different between the two groups.

Analysis of psychotic symptoms showed qualitative similarity in many of the psychiatric symptoms tested (though some incidence differences) between the two psychotic groups. The observation indicates the difficulty of symptoms-based discrimination between amphetamine positive and amphetamine negative acute psychosis (Table 2). Hallucinations including visual, auditory and paranoid were evident in both although the incidence of paranoid type of hallucination was significantly higher in amphetamine positive group in comparison with the other group (19\% vs. $10 \%$; p $<0.05$ respectively). As regards other psychotic symptoms, significant incidence ( $\mathrm{p}$ $<0.001$ ) of depression ( $44 \%$ vs. $13 \%$ ), ideas of reference ( $50 \%$ vs. $14 \%)$, and suspiciousness ( $44 \%$ vs. $11 \%)$ was also observed in amphetamine positive psychosis in 
Table 1. Demographic characteristics of patients with first episode psychosis: amphetamine positive versus amphetamine negative groups.

\begin{tabular}{|c|c|c|c|}
\hline $\begin{array}{l}\text { Demographic } \\
\text { data }\end{array}$ & $\begin{array}{l}\text { Amphetamine-positive } \\
\text { psychotic group }\end{array}$ & $\begin{array}{l}\text { Amphetamine nega- } \\
\text { tive psychotic group }\end{array}$ & $p$-value* \\
\hline Total number & 34 & 72 & \\
\hline Age (years)** & $23.3 \pm 9.4 * *$ & $19.8 \pm 7.1 * *$ & \\
\hline Sex: male & $34(100 \%)$ & $45(62.5 \%)$ & $<0.01$ \\
\hline female & - & $27(37.5 \%)$ & \\
\hline \multicolumn{4}{|c|}{ Marital status } \\
\hline married & $15(44 \%)$ & $31(43 \%)$ & \\
\hline unmarried & $19(60 \%)$ & $41(57 \%)$ & \\
\hline \multicolumn{4}{|c|}{ Education: } \\
\hline$<12$ years & $29(85 \%)$ & $66(92 \%)$ & \\
\hline$>12$ years & $5(15 \%)$ & $6(8.0 \%)$ & \\
\hline \multicolumn{4}{|l|}{ Employment: } \\
\hline employed & $9(27 \%)$ & $36(36 \%)$ & \\
\hline unemployed & $25(73 \%)$ & $46(64 \%)$ & \\
\hline \multicolumn{4}{|c|}{ Socioeconomic status } \\
\hline Low & $7(21 \%)$ & $17(24 \%)$ & \\
\hline Medium & $21(61 \%)$ & $47(65 \%)$ & \\
\hline High & $6(18 \%)$ & $8(11 \%)$ & \\
\hline \multicolumn{4}{|c|}{ Family history } \\
\hline $\begin{array}{l}\text { Poor family } \\
\text { support }\end{array}$ & $28(82 \%)$ & $49(68 \%)$ & $<0.05$ \\
\hline $\begin{array}{l}\text { Parental sub- } \\
\text { stance use }\end{array}$ & $9(27 \%)$ & $11(15 \%)$ & $<0.05$ \\
\hline $\begin{array}{l}\text { Parental mental } \\
\text { illness }\end{array}$ & $4(12 \%)$ & $31(43 \%)$ & $<0.01$ \\
\hline
\end{tabular}

Table 2. Comparison between amphetamine positive psychosis and amphetamine negative psychosis regarding psychiatric and autonomic symptoms \& signs.

Symptoms \& Amphetamine positive Amphetamine negative $p$-value signs psychotic group $(\mathrm{n}=34)$ psychotic group $(\mathrm{n}=72)$

\section{Psychiatric}

Hallucina-
tions

Visual $\quad 27 \%(9) \quad 18 \%(13)$

Auditory $\quad 74 \%(25) \quad 65 \%(47)$

$\begin{array}{lll}\text { Paranoid } & 29 \%(10) & 19 \%(14)\end{array}<0.05$

Depression $\quad 44 \%(15) \quad 13 \%(9) \quad<0.001$

Ideas of $\quad 50 \%(17) \quad 14 \%(10) \quad<0.001$

\begin{tabular}{|c|c|c|}
\hline $\begin{array}{l}\text { Suspicious- } \\
\text { ness }\end{array}$ & $44 \%(15)$ & $11 \%(8)$ \\
\hline
\end{tabular}

$\begin{gathered}\text { Violent be- } \\ \text { havior }\end{gathered}$
hav

Suicidal
ideations $\quad 38 \%(13) \quad 24 \%(17)$

$\begin{array}{cccc}\begin{array}{c}\text { Auto- } \\ \text { nomic** }^{* *}\end{array} & 29 \%(10) & 7 \%(5) & <0.01\end{array}$

*Chi-square; values in brackets are number of cases. ** Principally: dilated pupils, tachycardia and increased pulse pressure.

comparison with amphetamine negative group respecttively. On the other hand, both psychotic groups were similar in the incidence of other symptoms like violent behavior and suicidal ideations.

Amphetamine is one of the autonomic sympathomi-metic drugs. When autonomic manifestations related to amphetamine were checked in both groups of patients, dilated pupils, tachycardia and increased pulse pressure were significantly observed in amphetamine positive 
Table 3. Psychiatric symptomatology: mean scores on the Positive and Negative Symptom Scale (PANSS) between patients with amphetamine positive and amphetamine negative psychosis.

\begin{tabular}{|c|c|c|c|}
\hline $\begin{array}{c}\text { PANSS } \\
(\text { mean } \pm \text { SD) }\end{array}$ & $\begin{array}{l}\text { Amphetamine- } \\
\text { related psychotic } \\
\text { disorder }(n=34)\end{array}$ & $\begin{array}{l}\text { Amphetamine } \\
\text { negative psychosis } \\
(\mathrm{n}=72)\end{array}$ & $p$-value \\
\hline Positive & $18.3 \pm 4.1$ & $15.6 \pm 6.5$ & $<0.05$ \\
\hline Negative & $11.6 \pm 4.7$ & $21.3 \pm 7.3$ & $<0.01$ \\
\hline General & $28.5 \pm 5.6$ & $39.3 \pm 9.3$ & $<0.01$ \\
\hline Total & $58.4 \pm 8.7$ & $76.3 \pm 10.5$ & $<0.01$ \\
\hline
\end{tabular}

PANSS-PS = Positive and Negative Symptoms Scale.

psychotic group compared with the other group (29\% vs. $7 \% ; \mathrm{p}<0.01$ respectively).

Amphetamine-related psychotic patients (amphetamine positive group) showed significantly higher PANSS positive psychotic scores than amphetamine negative psychotic group. The later group had significantly higher scores for both the negative and general psychotic symptoms (Table 3). Personality disorder was evident among not less half of studied psychotic patients whether they were amphetamine positive or negative $(57 / 106 ; 54 \%)$. Table 4 showed significant incidence ( $p$ $<0.01$ ) of cluster B of personality disorder (e.g. antisocial, borderline) in amphetamine related psychotic group compared with the psychotic group negative to amphetamine ( $73.5 \%$ vs. $44 \%$; respectively). On the other hand, no difference in the incidence of the other two clusters of personality dis- order (cluster A \& cluster C) between the two groups of psychotic patients.

\section{Discussions}

The present study has revealed a prevalence of amphe-
Table 4. Personality Disorder among Patients with Amphetamine-related psychosis in comparison with amphetamine-negative psychosis.

\begin{tabular}{|c|c|c|c|}
\hline $\begin{array}{l}\text { Personality } \\
\text { Disorder }\end{array}$ & $\begin{array}{l}\text { Amphetamine-po } \\
\text { psychotic group (n }\end{array}$ & $\begin{array}{l}\text { etamine-n } \\
\text { tic group }\end{array}$ & $p$-value* \\
\hline All & $73.5 \%(25)$ & $44 \%(32)$ & $<0.01$ \\
\hline Clusters: & & & \\
\hline A & $15 \%(5)$ & $19 \%(14)$ & \\
\hline B & $38 \%(13)$ & $7 \%(5)$ & \\
\hline $\mathrm{C}$ & $21 \%(7)$ & $18 \%(13)$ & $<0.001$ \\
\hline
\end{tabular}

tamine use as defined in urine analysis among one third of a sample of Saudi patients who were diagnosed as first episode psychosis. Literature data showed a prevalence of substance use in people with first episode psychosis of approximately double that in the general population of similar age $[10,19,20]$. Also, individuals with first episode psychosis may have a trend of increased sensitivity (supersensitivity hypothesis) to develop substance use disorder [21,22]. The patients with positive amphetamine samples showed demographics of young age $(23.3 \pm 9.4$ years), all were men, and $60 \%$ were unmarried, a demographic criteria observed in amphetamine-related psychotic patients [23]. The high incidence of amphetamine use in the Saudi sample of patients (one third of the total) supports a previous report of increased trend of amphetamine use in Saudi subjects since year 2000 [12]. Also, the presence of male gender only in positive samples for amphetamine reflects the strong and close style of Saudi culture that might hinder facing the problem of possible drug abuse among females or forward them for treatment [12]. The early detection of substance use in patients with first episode psychosis has an important therapeutic implication for medical staff who usually focus in their effort on chronic, not first episode patients. Additionally, these patients underreport usually their abuse of drugs. Therefore, misdiagnosis and inappropriate medical treatment can happen [24].

The high concentrations of amphetamine in the positive urine samples of cases diagnosed as first episode psychosis suggests the strong association between the onset of first episode psychosis and amphetamine use [9, 25-27].

The poor family support and positive history of parental substance abuse in amphetamine positive psychotic patients compared with amphetamine negative group is a common finding observed in patients with substance userelated psychosis [28].

The psychotic symptoms were qualitatively similar in the two groups though they differ in between as regards their incidence (Table 2). This creates a difficult clinical situation of differential diagnosis between amphetaminerelated psychosis and functional (primary) psychosis [29]. Amphetamine class of drugs like amphetamine and me- 
thamphetamine is known to increase the levels of monoamines (principally, dopamine) centrally [30]. Therefore, exposure to these drugs in higher doses can play a role in creating, accelerating or aggravating psychotic symptoms like aggression, depression, hallucination and paranoia in patients with psychosis [31]. Auditory, visual and paranoid hallucinations as well as delusions of reference are typical symptoms not only in primary psychosis but also in amphetamines-induced psychosis [32,33]. In the current study, the significantly high prevalence of paranoid hallucinations in amphetamine positive psychotic Saudi patients is in agreement with previous studies [24, 27,34,35]. Amphetamine users may have a tendency to develop depression; a finding seen also in the present study among amphetamine positive psychotic group (44\%). Suicidal ideation showed non-significant difference in its incidence between the two groups ( $38 \%$ vs. $24 \%$ respectively). Similar result has been reported before [27]. Significant presence of autonomic symptoms in amphetamine positive cases in addition to the positive result of amphetamine in urine sample should draw the attention of the psychiatrist to consider the amphetamine-related psychosis beside the primary psychotic disorders when dealing with the psychotic symptoms clinically and therapeutically [20]. This concept is very important clinically as the psychiatrists may hospitalize the patients unnecessarily and start the long-terms courses of antipsychotic drugs that have the potential for serious side effects [36-38]. It should be mentioned here that this medical issue is not as simple as expected for the psychiatrist to differentially diagnose the case of psychosis if it is amphetamine related or functional especially there is considerable variability in the dose of amphetamine required and even the onset of psychotic symptoms [39]. Furthermore, the duration of psychotic symptoms is also variable so that in Japanese group of psychotic patients who were methamphetamine users, psychotic symptoms persisted for more than a month in $41 \%$ of them [40].

In the present study, positive psychotic symptoms were greater in amphetamine-related psychosis tan amphetamine negative group. This indicates that amphetamine use possibly affects positive but not negative symptoms of schizophrenia [35]. The less prominence of negative symptoms in amphetamine-related psychosis in comparison with amphetamine negative psychotic group may support the notion that substance use affects positive but may alleviate negative symptoms of schizophrenia $[20,36,41]$. Cigarette smoking has been found to increase the positive symptoms in schizophrenia which explains why $70 \%$ or even more of patients with schizophrenia in United States are nicotine dependents [36, 42].

In patients with psychoses, abnormal personality styles are ascribed to possible alteration in the neurobiological function of central neurotransmitters. In schizotypal personality disorder, an alteration in dopaminergic function is suggested while disturbance in serotonergic activity is suggested in subjects with borderline personality and antisocial personality disorders $[27,43,44]$. The observation of different clusters of personality disorders in psychotic Saudi patients irrespective amphetamine-related or not coincides with literature data of expected personality disorders in psychotic patients whether they were schizophrenic or non-schizophrenic $[45,46]$. Although the psychotic condition of many patients had stabilized before assessment of personality disorders, the significant high incidence of cluster B personality disorder especially antisocial personality in amphetamine positive psychotic patients (37\%) raises the question of whether cluster B disorder observed is just related to the psychotic element or an extension to the acute amphetamine use. Previous studies reported an association between amphetamine use and both violence, and antisocial behavior of the users $[47,48]$.

This study is the first study that investigates the incidence of amphetamine use in Saudi patients with first episode psychosis. The one-third incidence of positive samples for amphetamine among the studied Saudi patients raises the proposed question whether urine screening for possible drug abuse is necessary or not in patients with first episode psychosis. Our findings in addition to previous reports of the presence of substance misuse in the majority of people with first-episode psychosis that may have therapeutic implication $[19,49,50]$ may support urine screening for possible drug abuse among psychotics. On the contrary, other investigators have not found any effect of routine urine drug screening in a psychiatric emergency service on disposition or the subsequent length of inpatient stays. Their results did not support routine use of drug screens in this setting [32]. In the current Saudi study, assessment of the duration of stay in the hospital for both amphetamine positive versus amphetamine negative cases was missing. This is a weak point in our study that necessitates a further research to check. Another weak point in the study is that we did not assess the cost benefit relationship of routine screening in diagnosis, treatment and decision of disposition of the patient from the psychiatric emergency. The current study has also some limitations. Although the clinical condition of many patients had stabilized, some continued to have psychotic symptoms, which raises the question of whether the personality disorder evaluations were "colored" or not by the concomitant psychotic disorder. Also, subjects with amphetamine related psychosis and amphetamine negative psychosis must be followed up carefully and undergo re-evaluation over time.

Conclusions: The incidence of amphetamine use in 
Saudi patients with first episode psychosis is high. The study supports the screening of urine for amphetamine use in patients with acute psychosis. This laboratory marker in addition to other clinical and demographic parameters can help proper diagnosis. The diagnostic distinction between amphetamine related psychosis and other psychoses is critically important, because amphetamine psychosis requires a different management. Further studies on wider scale and larger number of Saudi psychotic patients are required to support our preliminary results.

\section{References}

[1] K. L. Barry, M. F. Fleming, J. R. Greenley, S. Kropp and P. Widlak, "Characteristics of Persons with Severe Mental Illness and Substance Abuse in Rural Areas," Psychiatric Services, Vol. 47, No. 1, January 1996, pp. 88-90.

[2] I. L. Fowler, V. J. Carr, N. T. Carter and T. J. Lewin, "Patterns of Current and Lifetime Substance Use in Schizophrenia," Schizophrenia Bulletin, Vol. 24, No. 3, 1998, pp. 443-455.

[3] R. G. McCreadie, Scottish Comorbidity Study Group, "Use of Drugs, Alcohol and Tobacco by People with Schizophrenia: Case-Control Study," The British Journal of Psychiatry, Vol. 181, October 2002, pp. 321-325. doi:10.1192/bjp.181.4.321

[4] K. T. Mueser, P. Nishith, J. I. Tracy, J. DeGirolamo and M. Molinaro, "Expectations and Motives for Substance Use in Schizophrenia," Schizophrenia Bulletin, Vol. 21, No. 3, 1995, pp. 367-378.

[5] L. Arseneault, M. Cannon, R. Poulton, R. Murray, A. Caspi and T. E. Moffitt, "Cannabis Use in Adolescence and Risk for Adult Psychosis: Longitudinal Prospective Study," British Medical Journal, Vol. 325, No. 7374, November 2002, pp. 1212-1213. doi:10.1136/bmj.325.7374.1212

[6] C. Curran, N. Byrappa and A. McBride, "Stimulant Psychosis: Systematic Review," The British Journal of Psychiatry, Vol. 185, September 2004, pp. 196-204. doi:10.1192/bjp.185.3.196

[7] E. Jacobs, D. Fujii, J. Schiffman and I. Bello, "An Exploratory Analysis of Neurocognition in Methamphetamine-Induced Psychotic Disorder and Paranoid Schizophrenia," Cognitive and Behavioral Neurology, Vol. 21, No. 2, June 2008, pp. 98-103. doi:10.1097/WNN.0b013e31816bdf90

[8] J. Addington and D. Addington, "Patterns, Predictors and Impact of Substance Use in Early Psychosis: A Longitudinal Study," Acta Psychiatrica Scandinavica, Vol. 115, No. 4, April 2007, pp. 304-309. doi:10.1111/j.1600-0447.2006.00900.x

[9] J. H. Barnett, U. Werners, S. M. Secher, K. E. Hill, R. Brazil, K. Masson, D. E. Pernet, J. B. Kirkbride, G. K. Murray, E. T. Bullmore and P. B. Jones, "Substance Use in a Population-Based Clinic Sample of People with First-Episode Psychosis," The British Journal of Psy- chiatry, Vol. 190, June 2007, pp. 515-520. doi:10.1192/bjp.bp.106.024448

[10] R. Cantwell, J. Brewin, C. Glazebrook, T. Dalkin, R. Fox, I. Medley and G. Harrison, "Prevalence of Substance Misuse in First-Episode Psychosis," The British Journal of Psychiatry, Vol. 174, February 1999, pp. 150-153. doi:10.1192/bjp.174.2.150

[11] S. I. A. Rahim, M. S. Abumadini, M. S. Khalil and T. Musa, "Long-Term Outcome of Treated Addiction in Saudi Arabia: Predictors of Relapse in 10 Year Followup," The Arab Journal of Psychiatry, Vol. 16, No. 2, November 2005, pp. 86-97.

[12] M. S. AbuMadini, S. I. A. Rahim, M. A. Al-Zahrani and A. O. AL-Johi, "Two Decades of Treatment Seeking for Substance Use Disorders in Saudi Arabia: Trends and Patterns in a Rehabilitation Facility in Dammam," Drug and Alcohol Dependence, Vol. 97, No. 3, October 2008, pp. 231-236. doi:10.1016/j.drugalcdep.2008.03.034

[13] Department of Health and Human Services, "Mandatory Guidelines for Federal Workplace Drug Testing Programs: Final guidelines notice," Federal Register, Vol. 53, 1989, pp. 11969-11989.

[14] A. Jablensky, J. McGrath, H. Herrman, D. Castle, O. Gureje and M. Evans, "Psychotic Disorders in Urban Areas: An Overview of the Study on Low Prevalence Disorders," The Australian and New Zealand of Psychiatry, Vol. 34, No. 2, April 2000, pp. 221-236. doi:10.1080/j.1440-1614.2000.00728.x

[15] S. R. Kay, L. A. Opler and J. P. Lindenmayer, "Reliability and Validity of the Positive and Negative Syndrome scale for Schizophrenics," Psychiatry Research, Vol. 23, No. 1, January 1988, pp. 99-110. doi:10.1016/0165-1781(88)90038-8

[16] S. R. Kay, L. A. Opler and J. P. Lindenmayer, "The Positive and Negative Syndrome Scale (PANSS): Rationale and Standardization," The British Journal of Psychiatry (Suppl), Vol. 7, November 1989, pp. 59-67.

[17] A. W. Loranger, N. Sartorius, A. Andreoli, P. Berger, P. Buchheim, S. M. Channabasavanna, B. Coid, A. Dahl, R. F. Diekstra, B. Ferguson, et al., "The Personality Disorder Examination: A Preliminary Report," Archives of General Psychiatry, Vol. 51, No. 3, March 1994, pp. 215224.

[18] A. W. Loranger, M. F. Lenzenweger, A. F. Gartner, V. L. Susman, J. Herzig, G. K. Zammit, J. D. Gartner, R. C. Abrams and R. C. Young, "Trait-State Artifacts and the Diagnosis of Personality Disorders," Archives of General Psychiatry, Vol. 48, No. 8, August 1991, pp. 720-728.

[19] S. Van Mastrigt, J. Addington and D. Addington, "Substance Misuse at Presentation to an Early Psychosis Program," Social Psychiatry and Psychiatry Epidemiology, Vol. 39, No. 1, January 2004, pp. 69-72. doi:10.1007/s00127-004-0713-0

[20] D. Wade, S. Harrigan, J. Edwards, P. M. Burgess, G. Whelan and P. D. McGorry, "Course of Substance Misuse and Daily Tobacco Use in First Episode Psychosis," Schizophrenia Research, Vol. 81, No. 2-3, January 2006, 
pp. 145-150. doi:10.1016/j.schres.2005.09.010

[21] V. M. Gonzalez, C. M. Bradizza, P. C. Vincent, P. R. Stasiewicz and N. D. Paas, "Do Individuals with a Severe Mental Illness Experience Alcohol and Drug-Related Problems? A Test of the Supersensitivity Hypothesis," Addictive Behaviors, Vol. 32, No. 3, March 2007, pp. 477-490. doi:10.1016/j.addbeh.2006.05.012

[22] D. Harris and S. L. Batki, "Stimulant Psychosis: Symptom Profile and Acute Clinical Course," The American Journal on Addiction, Vol. 9, No. 3, Winter 2000, pp. 28-37.

[23] N. Chivite-Matthews, A. Richardson, J. O'Shea, J. Becker, N. Owen, S. Roe, et al., "Drug Misuse Declared: Findings from 2003/2004 British Crime Survey," Home Office Statistical Survey, 2005.

[24] C. L. Caton, R. E. Drake, D. S. Hasin, B. Dominguez, P. E. Shrout, S. Samet and B. Schanzer, "Differences between Early Phase Primary Psychotic Disorders with Concurrent Substance Use and Substance-Induced Psychoses," Archives of General Psychiatry, Vol. 62, No. 2, February 2005, pp. 137-145. doi:10.1001/archpsyc.62.2.137

[25] M. J. Schiller, M. Shumway and S. L. Batki, "Patterns of Substance Use among Patients in an Urban Psychiatric Emergency Service," Psychiatric Services, Vol. 51, No. 1, January 2000, pp. 113-115.

[26] M. Lambert, P. Conus, D. I. Lubman, D. Wade, H. Yuen, S. Moritz, D. Naber and B. G. Schimmelmann, "The Impact of Substance Use Disorders on Clinical Outcome in 643 Patients with First Episode Psychosis," Acta Psychiatrica Scandinavics, Vol. 112, No. 2, August 2005, pp. 141-148. doi:10.1111/j.1600-0447.2005.00554.x

[27] L. Hides, S. M. Cotton, G. Berger, J. Gleeson, C. O’Donnell, T. Proffitt, P. D. McGorry and D. I. Lubman, "The Reliability and Validity of the Alcohol, Smoking and Substance Involvement Screening Test (ASSIST) in First Episode Psychosis," Addictive Behaviors, Vol. 34, No. 10, October 2009, pp. 821-25. doi:10.1016/j.addbeh.2009.03.001

[28] C. L. Caton, R. E. Drake, D. S. Hasin, B. Dominguez, P. E. Shrout, S. Samet and B. Schanzer, "Differences between Early Phase Primary Psychotic Disorders with Concurrent Substance Use and Substance-Induced Psychoses," Archives of General Psychiatry, Vol. 62, No. 2, February 2005, pp. 137-145.

doi:10.1001/archpsyc.62.2.137

[29] J. M. Brown, G. R. Hanson and A. E. Fleckenstein, "Regulation of the Vesicular Monoamine Transporter-2: A Novel Mechanism for Cocaine and Other Psychostimulants," Journal of Pharmacology and Experimental Therapeutics, Vol. 286, No. 3, March 2001, pp. 762-767.

[30] A. M. Barr, W. J. Panenka, G. W. MacEwan, A. E. Thornton, D. J. Lang, W. G. Honer and T. Lecomte, "The Need for Speed: An Update on Methamphetamine Addiction," Journal of Psychiatry \& Neuroscience, Vol. 31, No. 5, September 2006, pp. 301-313.

[31] C. K. Chen, S. K. Lin, P. C. Sham, D. Ball, E. W. Loh, C.
C. Hsiao, Y. L. Chiang, S. C. Ree, C. H. Lee and R. M. Murray, "Premorbid Characteristics and Co-Morbidity of Methamphetamine Users with and without Psychosis," Psychological Medicine, Vol. 33, No. 8, November 2003, pp. 1407-1414. doi:10.1017/S0033291703008353

[32] C. C. Cruickshank and K. R. Dyer, (2009). "A Review of the Clinical Pharmacology of Methamphetamine," Addiction, Vol. 104, No. 7, July 2009, pp. 1085-1099. doi:10.1111/j.1360-0443.2009.02564.x

[33] M. J. Schiller, M. Shumway and S. L. Batki, "Utility of Routine Drug Screening in a Psychiatric Emergency Setting," Psychiatric Servoces, Vol. 51, No. 4, April 2000, pp. 474- 478. doi:10.1176/appi.ps.51.4.474

[34] R. McKetin, J. McLaren, D. Lubman and L. Hides, “The Prevalence of Psychotic Symptoms among Methamphetamine Users," Addiction, Vol. 101, No. 4, April 2000, pp. 1473-1478.

[35] A. Baker, S. Bucci, T. J. Lewin, R. Richmond and V. J. Carr, "Comparisons between Psychosis Samples with Different Patterns of Substance Use Recruited for Clinical and Epidemiological Studies," Psychiatry Research, Vol. 134, No. 3, April 2005, pp. 241-250.

doi:10.1016/j.psychres.2005.02.006

[36] H. C. Margolese, L. Malchy, J. C. Negrete, R. Tempier and K. H. Gill, "Drug and Alcohol Use among Patients with Schizophrenia and Related Psychoses: Levels and Consequences," Schizophrenia Research, Vol. 67, No. 2-3, April 2004, pp. 157-66.

[37] A. Davies, M. A. Adena, N. A. Keks, S. V. Catts, T. Lambert and I. Schweitzer, "Risperidone Versus Haloperidol: Meta-Analysis of Efficacy and Safety," Clinical Therapeutics, Vol. 20, No. 1, January-February 1998, pp. 58- 71. doi:10.1016/S0149-2918(98)80034-9

[38] C. D. Carlson, P. A. Cavazzoni, P. H. Berg, H. Wei, C. M. Beasley and J. M. Kane, "An Integrated Analysis of Acute Treatment-Emergent Extrapyramidal Syndrome in Patients with Schizophrenia during Olanzapine Clinical Trials: Comparisons with Placebo, Haloperidol, Risperidone, or Clozapine," Journal of Clinical Psychiatry, Vol. 64, 2003, pp. 898-906. doi:10.4088/JCP.v64n0807

[39] B. M. Schanzer, M. B. First, B. Dominguez, D. S. Hasin and C. L. Caton, "Diagnosing Psychotic Disorders in the Emergency Department in the Context of Substance Use," Psychiatric Services, Vol. 57, No. 10, October 2006, pp. 1468-1473. doi:10.1176/appi.ps.57.10.1468

[40] D. S. Bell, "The Experimental Reproduction of Amphetamine Psychosis," Archives of General Psychiatry, Vol. 29, No. 1, July 1973, pp. 35-40.

[41] H. Ujiki and M. Sato, "Clinical Features of Sensitization to Methamphetamine Observed in Patients with Methamphetamine Dependence and Psychosis," Annals of the New York Academy of Sciences, Vol. 1025, October 2004, pp. 279-87. doi:10.1196/annals.1316.035

[42] M. A. Test, L. S. Wallisch, D. J. Allness and K. Ripp, "Substance Use in Young Adults with Schizophrenic Disorders," Schizophrenia Bulletin, Vol. 15, No. 3, 1989, pp. 465-4765. 
[43] C. J. Van Dongen, "Smoking and Persistent Mental Illness: An Exploratory Study," Journal of Psychosocial. Nursing and Mental Health Services, Vol. 37, No. 11, November 1999, pp. 26-34.

[44] M. Srisurapanont, R. Ali, J. Marsden, A. Sunga, K. Wada and M. Monteiro, "Psychotic Symptoms in Methamphetamine Psychotic in-Patients," The International Journal of Neuropsychopharmacology, Vol. 6, No. 4, December 2003, pp. 347-352. doi:10.1017/S1461145703003675

[45] D. Harris and S. L. Batki, "Stimulant Psychosis: Symptom Profile and Acute Clinical Course," The American Journal on Addiction, Vol. 9, No. 1, Winter 2000, pp. 28-37. doi:10.1080/10550490050172209

[46] I. I. Solano and M. G. DeChavez, "Premorbid Personality Disorders in Schizophrenia," Schizophrenia Research, Vol. 44, No. 2, August 2000, pp.137-144. doi:10.1016/S0920-9964(99)00203-0

[47] D. Lichtermann, E. Karbe and W. Maier, "The Genetic Epidemiology of Schizophrenia and of Schizophrenia
Spectrum Disorders," European Archives of Psychiatry and Neuroscience, Vol. 250, No.6, 2000, pp. 304-310. doi:10.1007/s004060070005

[48] M. S. Keshavan, H. S. Duggal, G. Veeragandham, N. M. McLaughlin, D. M. Montrose, G. L. Haas and N. R. Schooler, "Personality Dimensions in First-Episode Psychoses," The American Journal of Psychiatry, Vol. 162, No. 1, January 2005, pp. 102-109. doi:10.1176/appi.ajp.162.1.102

[49] J. C. Maxwell, "Emerging Research on Methamphetamine," Current Opinion in Psychiatry, Vol. 18, No. 3, May 2005, pp. 235-242. doi:10.1097/01.yco.0000165592.52811.84

[50] S. D. Gray, D. M. Fatovich, D. L. McCoubrie and F. F. Daly, "Amphetamine-Related Presentations to an InnerCity Tertiary Emergency Department: A Prospective Evaluation," The Medical Journal of Australia, Vol. 186, No. 7, April 2007, pp. 336-339. 